\title{
Effect of Nonnutritive Sucking on Infant Gastroesophageal Reflux
}

\author{
SUSAN R. ORENSTEIN \\ Department of Pediatrics, University of Pittsburgh School of Medicine and Children's Hospital of Pittsburgh, \\ Pittsburgh, PA 15213
}

\begin{abstract}
To evaluate the effect of pacifier use (nonnutritive sucking) on gastroesophageal reflux in infants, 48 infants younger than 6 months of age with pathologic reflux were prospectively evaluated with $\mathrm{pH}$ probe. In each infant, parameters of reflux were blindly quantified during paired periods in a cross-over design when pacifier use was either encouraged or prohibited. To determine whether positioning was a factor in the effect of nonnutritive sucking on reflux, 24 of the infants were studied seated and 24 studied prone. Pacifier use significantly affected only the frequency of reflux episodes, increasing it in prone infants from 7.2 \pm 1.1 to $12.8 \pm 2.3$ episodes $/ 120$ min postprandially $(p=$ 0.040 ) and decreasing it in seated infants, from $21.1 \pm 3.1$ to $14.8 \pm 2.6$ postprandially $(p=0.003)$ and from $17.3 \pm$ 4.8 to $5.9 \pm 0.9$ in the fasting period $(p=0.035)$. It did not significantly affect the clearance of reflux episodes or the total reflux time. These results suggest that infants with pathologic reflux frequency might best avoid pacifier use while in the beneficial prone position. When seated position is necessary, the pacifying effects of nonnutritive sucking may be useful in decreasing reflux events as well as in reducing crying behavior. (Pediatr Res 24: 38-40, 1988)
\end{abstract}

\section{Abbreviations}

GER, gastroesophageal reflux

NNS, nonnutritive sucking (pacifier use)

GER occurs frequently in infancy, when it may be pathologic by virtue of quantity (frequency or duration of episodes) or sequellae (caloric loss, esophageal irritation, or respiratory symptoms) (1). Therefore, it is of practical importance to identify any activities which affect reflux quantity.

NNS on a pacifier is also common in infants $(2,3)$. Although its behavioral effects have been extensively explored (4-9), its gastrointestinal effects have not received as much attention. Recently, the effects of NNS on maturation of the sucking reflex (accelerated), gastric emptying (no effect), intestinal transit time (slowed), nutrient absorption (no effect), and weight gain (increased) have been studied in premature infants $(10-14)$. However, the effect of pacifier use on GER has not been examined.

Swallowing relaxes the lower esophageal sphincter (15); lower esophageal sphincter relaxation may induce reflux episodes $(16$,

Received July 9, 1987; accepted February 29, 1988.

Correspondence and request reprints, Susan R. Orenstein, M.D., Division of Pediatric Gastroenterology, Children's Hospital of Pittsburgh, 3705 Fifth Avenue at DeSoto Street, Pittsburgh, PA 15213.

Supported in part by National Institutes of Health-Grant R23 HD21445 and by United States Public Health Service Grant RR-84 for the Clinical Research Center. Published in part in Gastroenterology 1988;94 (5, part 2): A335.
17). Swallowing has also been shown to hasten clearance of refluxed material from the esophagus $(18,19)$. Thus NNS might be hypothesized to increase the frequency of reflux episodes, decrease their duration, or both.

The present studies were designed to explore the short-term effects of NNS on GER in infants. The initial results, in 24 infants studied seated, were contrary to the hypothesis: the frequency of GER was significantly reduced by pacifier use. To determine whether this finding was due to the seated position, which is provocative for GER, a second group of 24 infants was studied prone using an otherwise identical protocol. In the prone position, NNS increased GER frequency, as hypothesized.

\section{METHODS}

Patients. Forty-eight infants younger than six months old evaluated with pH probe for GER between January 1986, and September 1987, were enrolled in the study. Twenty-four of the infants were studied in the seated position for both sessions of the cross-over design study, and 24 were studied prone for both sessions. Their parents gave informed consent to the protocol, which had been approved by the Human Rights Committee of Children's Hospital of Pittsburgh. The infants' characteristics are indicated in Table 1; each had pathologic reflux by virtue of quantity (on the initial $15 \mathrm{~h}$ of $\mathrm{pH}$ probe testing) and/or sequellae. During the enrollment period the only reasons for exclusion from the study of an infant younger than 6 months having $\mathrm{pH}$ probe testing were inability to assume the study position or to suck on a pacifier, lack of a bed in the Clinical Research Center, lack of parental consent, or absence of pathologic reflux during the first $15 \mathrm{~h}$ of $\mathrm{pH}$ probe testing.

$p H$ probe. The intraluminal esophageal $\mathrm{pH}$ probe (Microelectrodes MI-506, Londonderry, NH) was calibrated to $\mathrm{pH} 2$ and 7 and inserted to $87 \%$ of the distance from the nares to the lower esophageal sphincter (21), and the position confirmed in 26 of the patients radiographically. The probe and the reference electrode, applied to the patient's shoulder, were connected to the pH meter (Accumet 810, Fisher Scientific, Springfield, NJ), which was linked in turn to the strip chart recorder (Linseis L600, Princeton, NJ, or Anspec 1202, Ann Arbor, MI, at $10 \mathrm{~cm} /$ h).

Protocol. The evening before the study, the $\mathrm{pH}$ probe was inserted and the patient was transferred to the Clinical Research Center. Apple juice feedings (usually a total of three feedings, $\mathrm{pH}$ about 4 ) were given every 3 to $4 \mathrm{~h}$ until $0430 \mathrm{~h}$ to document pathologic reflux, which was present in each of the 48 infants. At 0430 and $1030 \mathrm{~h}$, to reduce hunger-related behavior, each infant was given a standard volume of his/her regular formula $(2 \mathrm{ml} / \mathrm{cm}$ of height; any residual volume not taken within 15 min was given immediately by nasogastric tube, and the tube immediately removed). At 0730 and $1330 \mathrm{~h}$, apple juice feedings 
Table 1. Patients

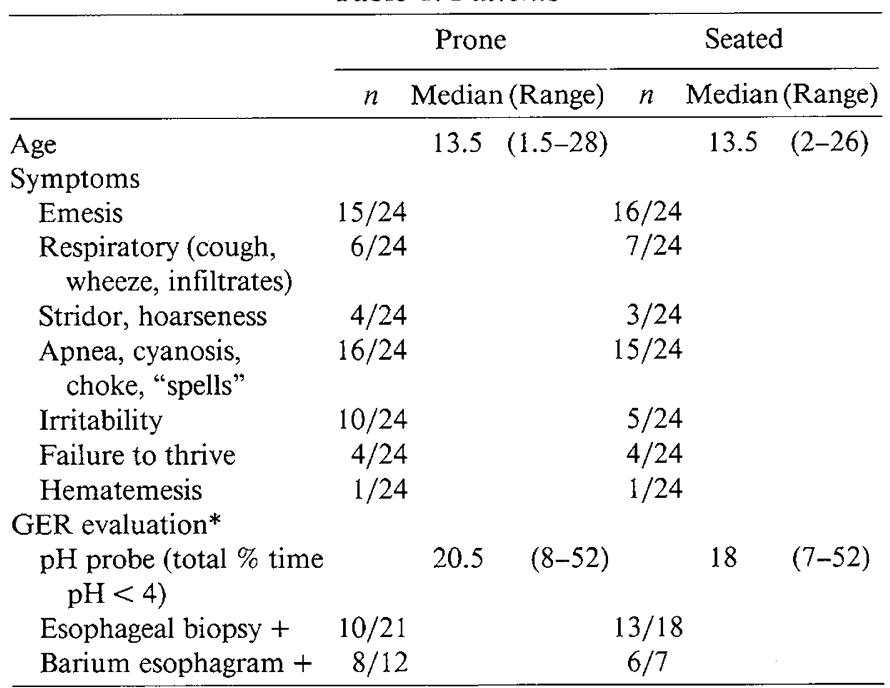

* Esophageal biopsy was considered positive $(+)$ if papillary height was more than $65 \%$ of the epithelial height, basal cell thickness was more than $20 \%$ of the epithelial height, or eosinophilic or polymorphonuclear leukocytes infiltrated the epithelium (20), barium esophagram was considered positive for reflux if reported so by the radiologist.

were given in the same standard volume and were followed by either of the two nearly 3-h study periods ("pacifier period" and "control period"), during which the 24 "seated" infants were seated at $60^{\circ}$ in an infant seat, the 24 "prone" infants were kept flat prone, and all infants were observed continuously by a Clinical Research Center nurse. The order of the pacifier and control periods was randomly assigned by lottery, with a block of 24 (22). During the lottery-assigned "pacifier period," the nurse encouraged sucking on a pacifier, replacing it any time it fell from the infant's mouth, and occasionally jiggling it to stimulate sucking if needed. During the "control period," no sucking was permitted on the pacifier or fingers.

Analysis. The $\mathrm{pH}$ probes were blindly analyzed for four commonly used measures of reflex frequency and duration during the 120 postprandial min and the subsequent fasting time for both the "control period" and the "pacifier period" for each infant. The four parameters evaluated were the total minutes with $\mathrm{pH}$ below 4 , the number of reflux episodes, the mean duration of reflux episodes, and the duration of the longest episode. A reflux episode was defined as beginning with a $\mathrm{pH}$ drop to below 4, and ending when the $\mathrm{pH}$ rose above 4 .

Each infant's control and pacifier fasting periods often differed slightly in duration, due to different durations of feeding, diapering, etc., at the beginning of the two study periods and the fixed time for the subsequent feeding, so the fasting time analyzed for each infant's pair of fasting periods was made identical in duration simply by eliminating the final minutes of the longer one from analysis. For analysis of fasting reflux parameters among subjects, a corrected score was assigned to the two parameters whose denominator is the duration of observation (i.e. the total minutes with $\mathrm{pH}$ below 4 and the number of reflux episodes). The corrected score was derived to extrapolate the data over a standard $2 \mathrm{~h}$ of fasting. Thus, the actual measurements for each of these two parameters in the fasting period were multiplied by $120 \mathrm{~min}$ and divided by the minutes in the subject's actual fasting periods, in order to give equal weight to infants observed for varying durations of fasting.

Wilcoxon signed rank test was used for comparisons between the control and pacifier periods for each measure of reflux during both postprandial and fasting periods within each group of 24 infants; significance was defined as $p<0.05$; data are expressed as mean $\pm \mathrm{SEM}$.

\section{RESULTS}

In seated infants, pacifier sucking significantly reduced the frequency of reflux episodes, both in the two-hour postprandial period and in the subsequent fasting period (Table 2). Although this reduced frequency with NNS was accompanied by a lower mean total duration of esophageal acidification, both postprandially and fasting, this did not reach significance in the 24 infants studied. Nonnutritive sucking did not improve measures of reflux clearance in seated infants: the mean duration of reflux episodes and the duration of the longest episode were not decreased by sucking on a pacifier.

However, in prone infants NNS significantly increased reflux frequency. The tendency of this increased frequency of episodes to be reflected in an increased total duration of reflux was blunted by the tendency toward improved clearance, although neither the total duration nor the mean duration of episodes was significantly affected by NNS. There was no effect of NNS on reflux parameters in the fasting period in prone infants.

\section{DISCUSSION}

In the prone position, NNS produced the expected increase in reflux frequency postprandially. This increase in GER frequency was presumably due to increased frequency of lower esophageal sphincter relaxation, due in turn to increased swallowing during NNS.

The idea that NNS increases swallowing frequency finds empiric support from esophageal motility studies performed with pacifiers $(23,24)$, although specific data regarding the effect of pacifier use on swallowing frequency in infants are lacking. Barium radiography of the esophagus provides further evidence that swallowing induced by NNS may provoke reflux episodes (25).

In the prone infants' fasting period, the lack of a corresponding increase in GER frequency with NNS may be due to the much lower gastric volume in that period, making it less likely that an episode of sphincter relaxation would produce an episode of reflux.

Table 2. Results*

GER

Total GER frequency

time (min/ (n/120 GER duration Longest GER

$120 \mathrm{~min})$ min) (min/episode) episode (min)

Prone

Postprandial

$\begin{array}{lcccc}\text { Control } & 49.8 \pm 7.4 & 7.2 \pm 1.1 & 8.9 \pm 1.9 & 32.0 \pm 6.1 \\ \text { Pacifier } & 54.5 \pm 6.4 & 12.8 \pm 2.3 & 7.1 \pm 1.2 & 29.7 \pm 4.3 \\ p= & \text { NS } & 0.040 & \text { NS } & \text { NS } \\ \text { Fasting } & & & & \\ \text { Control } & 17.9 \pm 5.8 & 5.4 \pm 1.7 & 3.0 \pm 1.4 & 4.8 \pm 2.0 \\ \text { Pacifier } & 10.5 \pm 3.7 & 4.4 \pm 1.8 & 1.5 \pm 0.6 & 2.2 \pm 0.8 \\ p= & \text { NS } & \text { NS } & \text { NS } & \text { NS }\end{array}$

Seated

Postprandial

Control $\quad 61.5 \pm 6.2 \quad 21.1 \pm 3.1 \quad 4.5 \pm 0.9 \quad 20.1 \pm 3.8$

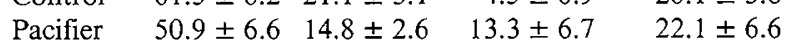

$\begin{array}{lllll}p= & \text { NS } & 0.003 & \text { NS } & \text { NS }\end{array}$

Fasting

Control

$41.8 \pm 8.1 \quad 17.3 \pm 4.8$

$4.1 \pm 1.3$

$5.8 \pm 1.4$

Pacifier

$30.5 \pm 7.5 \quad 5.9 \pm 0.9$

$4.1 \pm 1.2$

$5.3 \pm 1.4$

$p=\quad$ NS $\quad 0.035 \quad$ NS $\quad$ NS

* Data are reflux episodes (i.e. esophageal $\mathrm{pH}<4.0$ ); $p$ is determined by Wilcoxon signed rank test; NS is $p \geq 0.05$. For total GER time and GER frequency in fasting periods, raw data are multiplied by $120 \mathrm{~min}$ and divided by the actual minutes in the paired fasting periods to permit intersubject analysis. 
In the seated position, the contrary decrease in reflux frequency is not easily explained. The seated position is known to be provocative for reflux, particularly in contrast to the prone position (26), as is also suggested by this study's control period values for reflux frequency in the two positions. It is possible that in the face of the fundamental augmentation of reflux frequency by the seat, the observed decrease in reflux frequency with pacifier use might be caused indirectly, by way of the known effects of NHS on behavior, rather than directly, by way of an effect on the upper gastrointestinal tract. For example, the decreased crying produced by NNS (4-9) might produce decreased frequency of abdominal contractions, and thereby reduce reflux frequency (17). Whether this is the case is the subject of a study in progress.

The failure of this study to show any beneficial effect of NNS on reflux clearance in either position suggests that saliva quantity and swallowing frequency are not increased enough by NNS to have a significant impact on clearance. Thus, for example, there may be less saliva production with pacifier use in infants than with peppermint lozenge use in adults (18). Furthermore, esophageal acid clearance is a stepwise phenomenon that requires a number of swallows, so that normal adults, for example, require eight to 12 swallows taken at 30- to 60-s intervals to raise esophageal $\mathrm{pH}$ above 4 after a single esophageal bolus of $2 \mathrm{ml}$ to $15 \mathrm{ml}$ of $0.1 \mathrm{~N} \mathrm{HCl}(18,19)$. While it is possible that a type II error obscured an actual effect of NNS on clearance, even increasing the sample size by analyzing all 48 infants together does not demonstrate shortening of reflux episodes, which are $6.9 \pm 1.1 \mathrm{~min} /$ episode for the control period versus $10.2 \pm 3.4$ for the pacifier period, $p=0.42$.

The absence of effect of NNS on the total duration of esophageal acid exposure in either position suggests that pacifier use is unlikely to have an adverse or beneficial effect on infants with pathologic GER, except in instances where the change in frequency of reflux per se would be important. This might be the case, for example, for infants with failure to thrive due to increased frequency of "spitting." Although further study will be required to determine whether long-term effects of pacifier use will mimic those found in this evaluation of short-term use, these results suggest that infants with pathologic reflux frequency might best avoid pacifier use while in the beneficial prone position. When seated position is necessary, the pacifying effects of NNS may be useful in decreasing reflux events as well as in reducing crying behavior.

Acknowledgments. The author appreciates the participation of the infants and their families; the cooperation of the referring physicians and residents at Children's Hospital of Pittsburgh; the assistance of the Gastroenterology staff and the Clinical Research Center personnel; the blind readings of the $\mathrm{pH}$ probes by Vicki $\mathrm{S}$. Giarrusso; and the critical review of the manuscript by David M. Orenstein and Samuel A. Kocoshis.

\section{REFERENCES}

1. Herbst JJ 1981 Gastroesophageal reflux. J Pediatr 98:859-870

2. Zadik D, Stern N, Litner M 1977 Thumb- and pacifier-sucking habits. Am J Orthod 71:197-201

3. Koepke JE, Barnes P 1982 Amount of sucking when a sucking object is readily available to human newborns. Child Dev 53:978-983

4. Kessen W, Leutzendorff AM 1963 The effect of nonutritive sucking on movement in the human newborn. J Comp Physiol Psychol 56:69-72

5. Kessen W, Leutzendorff AM, Stoutsenberger K 1967 Age, food deprivation, nonnutritive sucking, and movement in the human newborn. $J$ Comp Physiol Psychol 63:82-86

6. Neeley CA 1979 Effects of nonnutritive sucking upon the behavioral arousal of the newborn. Birth Defects 15:173-200

7. Lambesis CC, Vidyasagar D, Anderson GC 1979 Effects of surrogate mothering on physiologic stabilization in transitional newborns. Birth Defects 15:201203

8. Field T, Goldson E 1984 Pacifying effects of nonnutritive sucking on term and preterm neonates during heelstick procedures. Pediatrics 74:1012-1015

9. Gunnar MR, Fisch RO, Malone S 1984 The effects of a pacifying stimulus on behavioral and adrenocortical response to circumcision in the newborn. $J$ Am Acad Child Psychol 23:34-38

10. Measel CP, Anderson GC 1979 Nonnutritive sucking during tube feedings: effect on clinical course in premature infants. J Obstet Gynecol Neonatal Nursing 8:265-272

11. Field T, Ignatoff E, Stringer S, Brennan J, Greenberg R, Widmayer S, Anderson GC 1982 Nonnutritive sucking during tube feedings: effects on preterm neonates in an intensive care unit. Pediatrics 70:381-384

12. Bernbaum JC, Pereira GR, Watkins JB, Peckham GJ 1983 Nonnutritive sucking during gavage feeding enhances growth and maturation in premature infants. Pediatrics 71:41-45.

13. Szabo JS, Hillemeier C, Oh W 1985 Effect of non-nutritive and nutritive suck on gastric emptying in premature infants.J Pediatr Gastroenterol Nutr 4:348351

14. DeCurtis M, McIntosh N, Ventura V, Brooke 01986 Effect of nonnutritive sucking on nutrient retention in preterm infants. J Pediatr 109:888-890

15. Goyal RK, Cobb BW 1981 Motility of the pharynx, esophagus, and esophageal sphincters. In: Johnson LR (ed) Physiology of the Gastrointestinal Tract. Raven Press, NY, pp 359-391

16. Dent J, Dodds WJ, Friedman RH, Sekiguchi T, Hogan WJ, Arndorfer RC, Petrie DJ 1980 Mechanisms of gastroesophageal reflux in recumbent asymptomatic human subjects. J Clin Invest 65:256-267

17. Werlin SL, Dodds WJ, Hogan WJ, Arndorfer RC 1980 Mechanisms of gastroesophageal reflux in children. J Pediatr 97:244-249

18. Helm JF, Dodds WJ, Riedel DR, Teeter BC, Hogan WJ, Arndorfer RC 1983 Determinants of esophageal acid clearance in normal subjects. Gastroenterol 85:607-612

19. Helm JF, Dodds WJ, Pelc LR, Palmer DW, Hogan WJ, Teeter BC 1984 Effect of esophageal emptying and saliva on clearance of acid from the esophagus. N Engl J Med 310:284-288

20. Leape LL, Bhan I, Ramenofsky 1981 Esophageal biopsy in the diagnosis of reflux esophagitis. J Pediatr Surg 16:379-384

21. Stroebel CT, Byrne WJ, Ament ME, Euler AR 1979 Correlation of esophageal lengths in children with height: application to the Tuttle test without prior esophageal manometry. J Pediatr 94:81-84

22. Lavoris PW, Louis TA, Bailar JC MII, Polasky M 1983 Designs for experiments-parallel comparisons of treatment. N Engl J Med 309:1291-1299

23. Gryboski JD, Thayer WR, Spiro HM 1963 Esophageal motility in infants and children. Pediatrics 31:382-395

24. Gryboski JD 1965 The swallowing mechanism of the neonate. I. Esophageal and gastric motility. Pediatrics 35:445-452

25. McCauley RGK, Darling DB, Leonidas JC, Schwartz AM 1978 Gastroesophageal reflux in infants and children: a useful classification and reliable physiologic technique for its demonstration. AJR 130:47-50

26. Orenstein SR, Whittington PF, Orenstein DM 1983 The infant seat as treatment for gastroesophageal reflux. N Engl J Med 309:760-763 